\title{
Association of a disintegrin and metalloprotease 33 gene polymorphisms with asthma
}

\author{
NIGELA YILIHAMU, QIMANGUL WUSHOUER, KADIRYAARKIN, HU XIN and UMESH YADAV \\ Department of Respiratory Medicine, The First Affiliated Hospital of Xinjiang Medical University, \\ Urumqi, Xinjiang 830011, P.R. China
}

Received February 4, 2014; Accepted May 14, 2014

DOI: $10.3892 / \operatorname{mco} .2014 .339$

\begin{abstract}
Various studies reported a disintegrin and metalloprotease 33 (ADAM33) as an important susceptibility gene for asthma, which is frequently detected among certain populations. The aim of the present study was to investigate the association between single-nucleotide polymorphisms (SNPs) of the ADAM33 gene and asthma. Our case-control study included 183 patients (73 male and 110 female, mean age $42.93 \pm 13.48$ years) who were admitted in the First Affiliated Hospital of Xinjiang Medical University between February, 2012 and May, 2013 and 155 healthy controls (66 male and 89 female, mean age $41.14 \pm 14.10$ years). Allelespecific polymerase chain reaction technology and DNA testing training methods were applied to detect the T2 and $\mathrm{ST}+5$ polymorphisms of the ADAM33 gene. The data were statistically analyzed to determine whether there exists an association between these genotypes and asthma-related morbidity. The genotypes and allele frequencies of the T2 and ST+5 SNPs of ADAM33 were not found to be significantly associated with asthma risk when compared between asthmatic patients and healthy controls $(\mathrm{P}>0.05)$. In addition, there was no association of the investigated SNPs with the severity of asthma. There was no significant difference in the forced vital capacity and the forced expiratory volume between patients with the ADAM33 T2 and ST+5 genotype. In conclusion, our results suggested that the $\mathrm{T} 2$ and $\mathrm{ST}+5$ ADAM33 gene polymorphisms do not confer a significant risk of asthma or affect its severity in the population investigated.
\end{abstract}

\section{Introduction}

Asthma is a major global health concern, primarily resulting from interactions between genetic and environmental factors.

Correspondence to: Professor Qimangul Wushouer, Department of Respiratory Medicine, The First Affiliated Hospital of Xinjiang Medical University, 137 Liyushan Road, Urumqi, Xinjiang 830011, P.R. China

E-mail: qimenw@hotmail.com

Key words: a disintegrin and metalloprotease 33 gene, single-nucleotide polymorphism, Uyghur, asthma
A significant association was previously demonstrated between single-nucleotide polymorphisms (SNPs) and haplotypes of the a disintegrin and metalloprotease 33 (ADAM33) gene and asthma in ethnically diverse populations (1). An association with ADAM33 variants in adult-onset asthma has been reported in several populations (2-4). However, the majority of the currently available data on ADAM33 and asthma have been obtained from Caucasians, whereas the availability of data on ADAM33 SNP association with asthma in Asian populations is limited. Certain studies reported no significant association between SNPs and asthma susceptibility in the Chinese and other populations $(5,6)$. The precise biological role of ADAM33 gene polymorphisms in asthma remains to be elucidated. Sharma et al (6) recently reviewed the association of all investigated ADAM33 gene polymorphisms with asthma worldwide and concluded that causal polymorphisms have yet to be identified. Data from different populations are available, demonstrating the association between ADAM33 gene polymorphisms and asthma; however, no study has yet demonstrated an association of SNPs T2 and ST+5 with asthma in the Chinese Uyghur population.

Xinjiang is located at the middle of the Silk Road that once extended from Rome to China. Several ethnicities, such as the Uyghur (48\%), Han (38\%) and Kazakh people (7\%), reside in this area (7). The Uyghurs are a Mongoloid-Caucasoid mixed population living in Northwest China who are mainly herdsmen or peasants in pastures. The Uyghur religion, lifestyle and customs differ from those of other Chinese ethnic groups; they live under relatively fixed conditions over a long period of time, which favors the development of a specific population and the stability of certain genes. It was previously demonstrated that the Uyghur allele distribution differs distinctly from that of other populations in Northwest China, such as Han, Hui and Mongolian.

The present study was conducted to investigate the role of ADAM33 SNPs T2 and ST+5 in asthma in the Chinese Uyghur population of Xinjiang.

\section{Materials and methods}

Subjects. This study included 183 unrelated adults with a clinical diagnosis of asthma (mean age, $42.93 \pm 13.48$ years; range, 18-80 years) and 155 healthy control subjects (mean age, $41.14 \pm 14.07$ years; range, $18-71$ years). The subjects were 
recruited between February, 2012 and May, 2013 at the Department of Respiratory Medicine, Xinjiang Medical University, Xinjiang, Urumuqi, China. There were no statistically significant differences in age and gender between the two groups $(\mathrm{P}>0.05)$. The diagnosis of suspected asthma was confirmed and the severity of asthma attacks was assessed according to the 2008 revision of the diagnostic criteria of the Chinese Medical Association for Respiratory Diseases (Asthma Study Group ) (8).

All the subjects met the following criteria: i) no family history of diseases involving the candidate genes, such as immune system diseases; ii) no other severe diseases, such as severe infections, new-onset myocardial infarction or stroke, or history of atopy; and iii) long-term residence in the Xinjiang area (third generation or more).

The study protocol was reviewed and approved by the Ethics Committee of Xinjiang Medical Hospital and written informed consent was obtained from all the participants.

Reagents and instruments. The Genomic DNA Isolation kit (catalog no., SK8224) was purchased from Sangon Biotech Co., Ltd. (Shanghai, China). The PCR reaction contained TaqDNA polymerase, $10 \mathrm{X}$ polymerase chain reaction (PCR) buffer without $\mathrm{Mg}^{2+}\left[100 \mathrm{mM}\right.$ Tris- $\mathrm{HCl}, \mathrm{pH} 8.8$ at $25^{\circ} \mathrm{C} ; 500 \mathrm{mM} \mathrm{KCl} ; 0.8 \%$ (v/v) Nonidet], $25 \mathrm{mM}$ magnesium chloride $\left(\mathrm{MgCl}_{2}\right)$, and $10 \mathrm{mM}$ deoxyribonucleoside triphosphates (dNTPs), all purchased from Sangon Biotech Co. The DNA marker was purchased from BBI Canada Inc. (Markham, ON, Canada), and the 6X DNA Loading dye from Sangon Biotech Shanghai, China). The PCR products were purified on with the DNA extraction kit (catalog SK1141; Sangon Biotech), and the restriction endonuclease for the digestion of DNA was purchased from MBI Fermentas (Beijing, China). The PCR amplification reaction was performed using a PCR thermocycler (BBI Canada Inc.) on a SW-CJ-1D clean bench (Jiang Su Sujie purification plant). A DK-8D-type electric heated tank (Hysen letter Experimental Instrument Co.) was used to digest the sample. Additional instruments used in this study were: a DYY-8 regulator steady flow electrophoretic to maintain a stable electric volume (Hai Qite Analytical Instruments Co., Ltd., Dalian, China); a YXJ-2 centrifuge machine (Gordon Ltd., Shanghai, China). a H6-1 micro-electrophoresis tank (Shanghai Xingyi Plexiglas Co., Ltd., Shanghai, China); a Gene Genius gel imaging system by Alibaba Co. (Beijing, China); a U-3010 UV spectrophotometer (Hitachi Co., Tokyo, Japan); and pipettes (range, 100-1,000, 20-200, and 0.5-10 $\mu$ l) by BBI Canada Inc.

Genomic DNA extraction. Peripheral venous whole-blood samples $(2 \mathrm{ml})$ from all the subjects were collected in EDTA anticoagulant tubes and stored at $-80^{\circ} \mathrm{C}$. The Genomic DNA Isolation kit (SK8224; Sangon Biotech, Co., Ltd.) was used for genomic DNA extraction according to the manufacturer's protocol.

ADAM33 genotyping by polymerase chain reacytion fragment length polymorphism. The preliminary determination of genetic samples were performedby Bioengineering Co., Ltd. (Shanghai, China). The primers used were as follows: T2 (rs2280090) forward (F), 5-AGGCTTTGAATCCAGGTCC-3, and reverse (R), 5-GGCAATAACCCACTCAGGAT-3; ST+5
Table I. Description of study population.

\begin{tabular}{lcc}
\hline Characteristics & Cases & Control \\
\hline No. of patients & 183 & 155 \\
Age, years & $42.93 \pm 13.48$ & $41.14 \pm 14.07$ \\
(mean \pm SD) & & \\
Gender, no. $(\%)$ & & $66(42.58)$ \\
Male & $73(39.89)$ & $89(57.42)$ \\
Female & $110(60.11)$ & $104.21 \pm 8.20$ \\
FEV1\% (mean \pm SD) & $70.96 \pm 17.44$ &
\end{tabular}

FEV1, forced expiratory volume; SD, standard deviation.

(rs597980) F, 5-CTCTGTCTCACCAGTTTTCGG-3, and R, 5-TTATGTGACTCCCCACTCCG-3. The PCR reaction for the amplification of $\mathrm{T} 2$ and $\mathrm{ST}+5$ was performed on atotal volume of $15 \mu \mathrm{l}$, containing $0.5 \mu \mathrm{l}$ of DNA, $1.5 \mu \mathrm{l}$ of $10 \mathrm{X}$ TaqDNA polymerase buffer, $0.3 \mu \mathrm{l}$ of dNTPs, $0.1 \mu \mathrm{l}$ of TaqDNA polymerase, $1.2 \mu \mathrm{l}$ of $\mathrm{MgCl}_{2}, 0.4 \mu \mathrm{l}$ of primers, TaqDNA polymerase $0.1 \mu \mathrm{l}$, and $11 \mu \mathrm{l}$ of double distilled water. The cycling conditions were: initial denaturation at $95^{\circ} \mathrm{C}$ for $5 \mathrm{~min} ; 40$ cycles of denaturation at $95^{\circ} \mathrm{C}$ for $30 \mathrm{sec}$; annealing at $68 / 67.5^{\circ} \mathrm{C}$ for $45 \mathrm{sec}$; and extension at $72^{\circ} \mathrm{C}$ for $60 \mathrm{sec}$; final extension at $72^{\circ} \mathrm{C}$ for $6 \mathrm{~min}$. The digestion reaction was performed in a total volume of $15 \mu \mathrm{l}$, containing contain $10 \mu \mathrm{l}$ of the PCR products, $1.5 \mu \mathrm{l}$ of the $10 \mathrm{X}$ buffer R (Received data buffer), $0.1 \mu \mathrm{l}$ of endonuclease (both from Sangon Biotech Co.), and $3.4 \mu \mathrm{l}$ of double distilled water. The samples were digested overnight at $37^{\circ} \mathrm{C}$.

Electrophoresis. The digestion products were run on a $3 \%$ agarose gel containing ethidium bromide at a voltage of $150 \mathrm{~V}$ for $30 \mathrm{~min}$. Band detection was then performed on a gel imaging system. Based on the acquired images, genotyping data were then entered into a NCBI database.

ADAM33 gene (T2 and ST+5) and its association with lung function. Of the 183 patients carrying the ADAM33 gene, 149 were asthmatic. The percentage of predicted forced expiratory volume in $1 \mathrm{sec}(\mathrm{FEV} 1 \%)$ and percentage of predicted forced vital capacity (FVC\%) were compared between the two groups, respectively.

Statistical analyses. Statistical analysis was performed using SPSS software, version 17.0 (SPSS Inc., Chicago, IL, USA). The Hardy-Weinberg equilibrium (HWE) was calculated using the $\chi^{2}$ test, with expected frequencies derived from the actual frequencies of each SNP in both groups. Measurement data results are expressed as means \pm standard deviation. Statistical significance was set at $\mathrm{P}=0.05$. The two groups of genotypes were compared using analysis of variance, applying the LSD t-test.

\section{Results}

Subject characteristics. As shown in Table I, there were no significant differences in gender and age between the two 
Table II. Genotype and allele distribution of ADAM33 gene polymorphisms.

\begin{tabular}{lccccccccc}
\hline Genotype & $\begin{array}{c}\text { Patient no. } \\
(\mathrm{n}=183)\end{array}$ & $\begin{array}{c}\text { Control no. } \\
(\mathrm{n}=155)\end{array}$ & $\chi^{2}$ & P-value & Allele & $\begin{array}{c}\text { Patient no. } \\
(\mathrm{n}=366)\end{array}$ & $\begin{array}{c}\text { Control no. } \\
(\mathrm{n}=310)\end{array}$ & $\chi^{2}$ & P-value \\
\hline T2 & & & & & & & & & \\
AA & 4 & 6 & 0.830 & 0.362 & $\mathrm{~A}$ & 42 & 44 & 1.117 & 0.291 \\
AG & 34 & 32 & 0.588 & 0.443 & $\mathrm{G}$ & 324 & 266 & & \\
GG & 145 & 117 & 0.667 & 0.410 & & & & & \\
ST+5 & & & & & & & & & \\
TT & 37 & 35 & 0.276 & 0.599 & $\mathrm{C}$ & 216 & 175 & 0.453 & 0.501 \\
CT & 76 & 65 & 0.006 & 0.940 & $\mathrm{~T}$ & 150 & 135 & & \\
CC & 70 & 55 & 0.279 & 0.597 & & & & & \\
\hline
\end{tabular}

ADAM33, a disintegrin and metalloprotease 33.

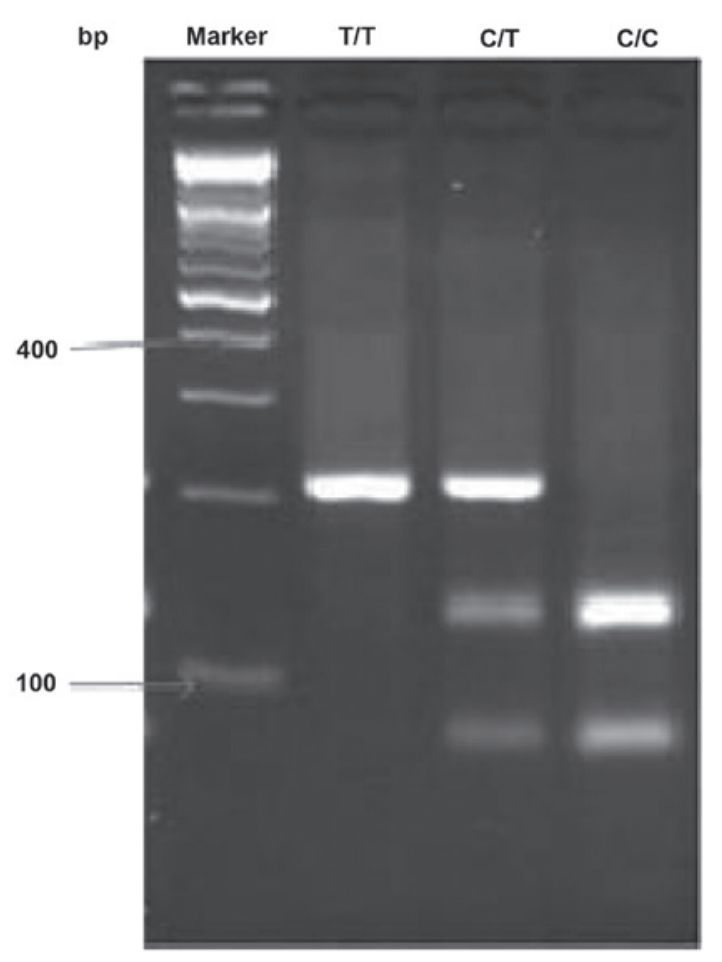

Figure 1. DNA marker genotypes T/T C/T C/C.

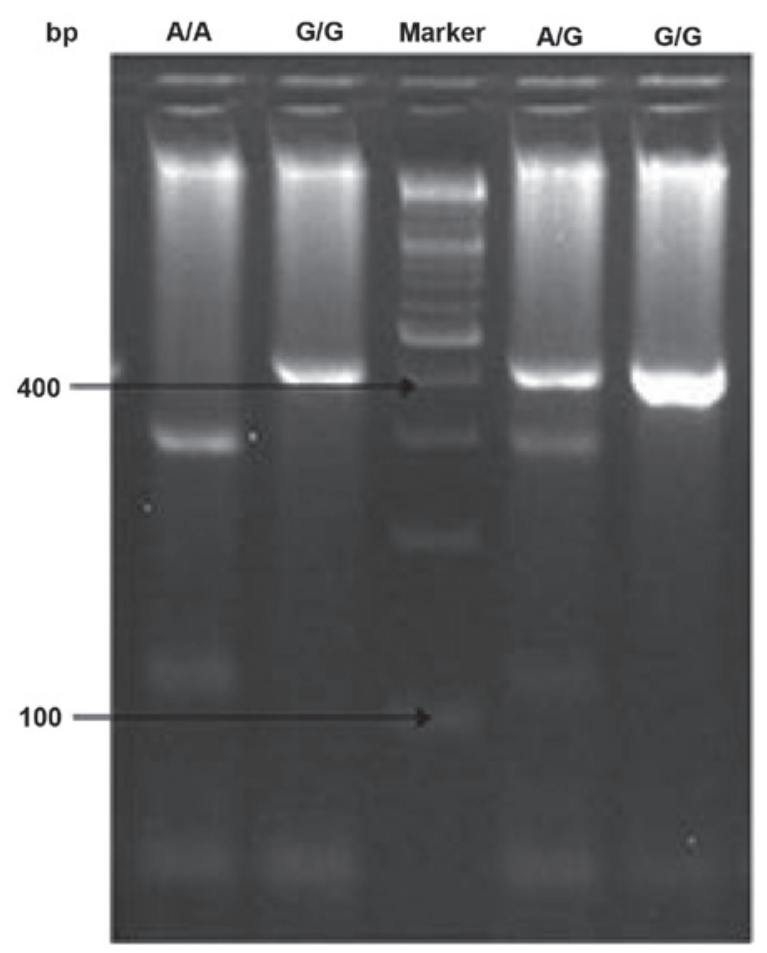

Figure 2. DNA marker genotypes G/G A/A A/G. groups. As regards lung function tests, there was a significant difference in FEV1\% between asthmatic patients and healthy controls $(70.96 \pm 17.44$ vs. $104.21 \pm 8.20, \mathrm{P}<0.05)$. Conventional risk factors, including a history of allergy and a family history of asthma, were higher among asthma patients.

Product and restriction fragment length polymorphism analysis of ADAM33 gene amplified by PCR. The ST+5 polymorphism genotype is for the $\mathrm{C} / \mathrm{T}$, following the PCR, the product was 206-bp in length. The digestion of the PCR product yielded 206-bp bands in TT homozygotes, 128- and 78-bp bands in CC homozygotes and all three bands in heterozygotes (Fig. 1). The T2 polymorphism genotype is for the $\mathrm{A} / \mathrm{G}$, following the PCR, the product was 425-bp in length. The digestion of the product yielded 402- and 23-bp bands in
GG homozygotes, 289-, 113- and 23-bp bands in AA homozygotes and all four bands in heterozygotes (Fig. 2).

Distribution of ADAM33 gene polymorphisms. As regards the $\mathrm{T} 2$ and $\mathrm{ST}+5$ polymorphisms, the asthmatic patients $\left(\chi^{2}=1.338\right.$ and 3.663 , respectively; $\left.P>0.05\right)$ and healthy controls $\left(\chi^{2}=3.601\right.$ and 3.353 , respectively; $\left.\mathrm{P}>0.05\right)$ were in HWE. There were no significant differences in the distribution of the genotypes and alleles of ADAM33 T2 $(\mathrm{P}=0.291)$ and $\mathrm{ST}+5(\mathrm{P}=0.501)$ between asthmatic patients and healthy controls (Table II).

Haplotype frequencies of the ADAM33 gene. The haplotype structure was analyzed using two SNPs (T2 and ST+5) and nine haplotypes were identified in the two groups (Table III). 
Table III. Frequencies of SNP haplotypes.

\begin{tabular}{|c|c|c|c|c|c|c|}
\hline \multirow[b]{3}{*}{ Haplotype } & \multirow{2}{*}{\multicolumn{2}{|c|}{ SNP position }} & \multicolumn{2}{|c|}{ Haplotype frequency } & \multirow[b]{3}{*}{$\chi^{2}$} & \multirow[b]{3}{*}{ P-value } \\
\hline & & & \multirow{2}{*}{$\begin{array}{c}\text { Patient no. } \\
(\mathrm{n}=183)\end{array}$} & \multirow{2}{*}{$\begin{array}{c}\text { Control no. } \\
(\mathrm{n}=155)\end{array}$} & & \\
\hline & $\mathrm{T} 2$ & $\mathrm{ST}+5$ & & & & \\
\hline 1 & GG & TT & 37 & 34 & & \\
\hline 2 & $\mathrm{AG}$ & $\mathrm{TT}$ & 0 & 1 & 1.072 & 0.300 \\
\hline 3 & AA & $\mathrm{TT}$ & 0 & 0 & - & - \\
\hline 4 & GG & $\mathrm{CC}$ & 48 & 33 & 0.784 & 0.376 \\
\hline 5 & $\mathrm{AG}$ & $\mathrm{CC}$ & 18 & 15 & 0.054 & 0.817 \\
\hline 6 & $\mathrm{AA}$ & $\mathrm{CC}$ & 4 & 5 & 0.188 & 0.665 \\
\hline 7 & GG & $\mathrm{CT}$ & 59 & 48 & 0.157 & 0.692 \\
\hline 8 & $\mathrm{AG}$ & $\mathrm{CT}$ & 17 & 18 & 0.118 & 0.732 \\
\hline 9 & AA & $\mathrm{CT}$ & 0 & 1 & 1.072 & 0.300 \\
\hline
\end{tabular}

SNP, single-nucleotide polymorphism.

Table VI. Genotype distribution of ADAM33 gene polymorphisms among asthmatic patients. ${ }^{2}$

\begin{tabular}{lccc}
\hline Genotype & $\begin{array}{c}\text { Patient no. } \\
(\mathrm{n}=149)\end{array}$ & FEV1\% & FVC\% \\
\hline T2 & & & \\
AA & 4 & $74 \pm 31$ & $86 \pm 25$ \\
AG & 29 & $74 \pm 15$ & $85 \pm 13$ \\
GG & 116 & $70 \pm 17$ & $86 \pm 15$ \\
F-value & & 0.763 & 1.164 \\
P-value & & 0.468 & 0.315 \\
ST+5 & & & \\
TT & 65 & $72 \pm 17$ & $84 \pm 14$ \\
CT & 57 & $70 \pm 17$ & $78 \pm 15$ \\
CC & 27 & $70 \pm 20$ & $81 \pm 18$ \\
F-value & & 0.222 & 2.233 \\
P-value & & 0.802 & 0.111 \\
\hline
\end{tabular}

ADAM33, a disintegrin and metalloprotease 33; FEV, forced expiratory volume; FVC, forced vital capacity. a'we selected 183 patients from the 149 to compare lung function test.

There was no significant difference in the distribution of haplotypes between asthmatic patients and healthy controls.

Association of the ADAM33 phenotypes with FEV1\% and $F V C \%$. As regards the $\mathrm{T} 2$ and $\mathrm{ST}+5$ polymorphisms (Table IV), there was no significant difference in FEV1\% and FVC\% among the different genotypes.

\section{Discussion}

In this study, we analysed the $\mathrm{T} 2$ and $\mathrm{ST}+5$ polymorphisms of the ADAM33 gene to investigate their association with asthma. This association was previously investigated in Asian populations with inconclusive results $(9,10)$. Over the last few years, a number of studies demonstrated that ADAM33 SNPs are significantly associated with asthma in different populations, including the Han Chinese; however, no single SNP of the ADAM33 gene (T2 and ST+5) was found to be associated with asthma across all the studies published thus far in the Uyghur population. We did not identify any association of individual SNPs with the presence of asthma or its severity.

The ADAM33 gene is located on chromosome 20p13 and 37 SNPs were initially identified (11). The identification of ADAM33 as an asthma susceptibility gene marks the entry of asthma research into the genomic area and provides a new insight to the understanding of the molecular basis underlying the pathogenesis of asthma. The heterogeneity of this disease may be attributed to different mutations within the gene and a combined effect of gene-gene and gene-environment interactions $(12,13)$. Another possible reason may be that the linkage disequilibrium patterns that exist between the identified SNPs in the gene may differ among different populations (9). Four SNPs (F+1, S1, ST+5 and V4) were previously found to be significantly associated with specific airway resistance at the age of 5 years $(\mathrm{P}<0.04)$ when children aged 3 and 5 years were investigated, but no study reported a positive association with $\mathrm{T} 2$ and $\mathrm{ST}+5$ in older populations (9). The polymorphisms were found to be associated with reduced lung function at the ages of 3 and 5 years, with a more significant association with the age of 5 years, which may reflect the increased sample size. ADAM33 polymorphisms were originally shown to be associated with bronchial hyperresponsiveness. In previous studies, T1, T2, S2 and V-3 sites were reported among Japanese adult populations $(14,15)$, whereas they were negative in this study. Minor alleles of the ADAM33 SNPs S+1, ST+4 and T2 were overtransmitted to the asthma-affected offspring, unlike any particular haplotype. In a study on Chinese subjects, adult asthma was associated with ADAM33 SNPs V4, T2, T1 and Q-1, but not with $\mathrm{T}+1$ and $\mathrm{S} 1$, or with $\mathrm{V} 4$ and $\mathrm{T}+1$, whereas the association with $\mathrm{T} 1$ sites was found to be significant (16), which proves that there is a difference in genetic association among different population in China, particularly between the 
Han and Uyghur Chinese people. The potential mechanism underlying the association of the T1 locus SNP with asthma may be that the T1 locus SNP leads to decreased FEV1 and increased susceptibility to asthma. There was no significant difference in the FVC and the FEV1 between patients with ADAM33 gene genotypes T2 and ST+5 in this study, as shown in Table IV.

A possible role for the ADAM33 gene in childhood asthma was excluded in a Mexican population and in a Caucasian population of North America (17,18). A particular subset of SNPs may represent a risk factor for asthma in Caucasians, whereas a different subset may increase the risk in Asian populations. However, no SNP has been consistently associated with asthma across ethnically diverse groups, similar to this study. Therefore, different SNPs of the ADAM33 gene may contribute to asthma susceptibility in specific ethnic populations. Additional studies with a larger sample size and long-term follow-up may lead to a more thorough understanding of the role of the T2 and ST+5 ADAM33 gene polymorphisms in the Uyghur population. Considering that the limited sample size may yield relative risk estimates lacking adequate precision, extended analyses with a larger sample size should be performed on patients of different ethnic origins to further verify this association.

In conclusion, our results revealed no association between the T2 and ST+5 ADAM33 gene polymorphisms and asthma in the Chinese Uyghur population of Xinjiang. Further investiagtion of the SNPs in genes surrounding ADAM33 is required and should specifically address the molecular mechanisms that may confer asthma susceptibility. The replication of consistent allelic associations in additional populations may help resolve this issue.

\section{Acknowledgements}

This study was supported by the National Natural Science Foundation of China (grant no. 81160004).

\section{References}

1. Howard TD, Postma DS, Jongepier H, et al: Association of a disintegrin and metalloprotease 33 (ADAM33) gene with asthma in ethnically diverse populations. J Allergy Clin Immunol 4: $717-722,2003$
2. Thongngarm T, Jameekornrak A, Limwongse C, et al: Association between ADAM33 polymorphisms and asthma in a Thai population. Asian Pac J Allergy Immunol 26: 205-211, 2008.

3. Bijanzadeh M, Ramachandra NB, Mahesh PA, et al: Association of IL-4 and ADAM33 gene polymorphisms with asthma in an Indian population. Lung 188: 415-422, 2010.

4. Awasthi S, Tripathi P, Ganesh S and Husain N: Association of ADAM33 gene polymorphisms with asthma in Indian children. J Hum Genet 56: 188-195, 2011.

5. Wang P, Liu QJ, Li JS, et al: Lack of association between ADAM33 gene and asthma in a Chinese population. Int J Immunogenet 33: 303-306, 2006.

6. Sharma N, Tripathi P and Awasthi S: Role of ADAM33 gene and associated single nucleotide polymorphisms in asthma. Allergy Rhinol (Providence) 2: 63-70, 2011.

7. Mayinu and Chen X: Evaluation of LOXL1 polymorphisms in exfoliation syndrome in the Uygur population. Mol Vis 17: 734-744, 2011.

8. Branch of ChineseMedicalAssociation for Respiratory Diseases (BCMARD): Bronchialasthmatherapeutic guidelines (definition, diagnosis, treatment of bronchial asthma). Chin J Tuberc RespirDis 31: 177-185, 2008 (In Chinese).

9. Vercelli D: Genetics, epigenetic, and the environment: switching, buffering, releasing. J Allergy Clin Immunol 113: 381-386, 2004.

10. van Diemen CC, Postma DS, Vonk JM, Bruinenberg M, Schouten JP and Boezen HM: A disintegrin and metalloprotease 33 polymorphisms and lung function decline in the general population. Am J Respir Crit Care Med 172: 329-333, 2005.

11. Van Eerdewegh P, Little RD, Dupuis J, et al: Association of the ADAM33 gene with asthma and bronchial hyperresponsiveness. Nature 418: 426-430, 2002.

12. Postma DS and Howard T: ADAM33 gene: confirming a gene without linkage. Clin Exp Allergy 34: 1-3, 2004.

13. Simpson A, Maniatis N, Jury F, et al: Polymorphisms in a disintegrin and metalloprotease 33 (ADAM33) predict impaired early-life lung function. Am J Respir Crit Care Med 172: 55-60, 2005.

14. Noguchi E, Ohtsuki Y, Tokunaga K, et al: ADAM33 polymorphisms are associated with asthma susceptibility in a Japanese population. Clin Exp Allergy 36: 602-608, 2006.

15. Sakagami T, Jinnai N, Nakajima T, et al: ADAM33 polymorphisms are associated with aspirin-intolerant asthma in the Japanese population. J Hum Genet 52: 66-72, 2007.

16. Su D, Zhang X, Sui H, et al: Association of ADAM33 gene polymorphisms with adult allergic asthma and rhinitis in a Chinese Han population. BMC Med Genet 9: 82, 2008.

17. Lind DL, Choudhry S, Ung N, et al: ADAM33 is not associated with asthma in Puerto Rican or Mexican populations. Am J Respir Crit Care Med 168: 1312-1316, 2003.

18. Raby BA, Silverman EK, Kwiatkowski DJ, et al: ADAM33 polymorphisms and phenotype associations in childhood asthma. J Allergy Clin Immunol 113: 1071-1078, 2004. 